\title{
Advance Pedagogy: Innovative Methods of Teaching and Learning
}

\author{
C. M. Khairnar
}

\begin{abstract}
Advance pedagogy is the way to enhance teaching and learning performance. Different innovative teaching methods are now in use across the globe. Hybrid teaching includes e learning in addition to the face to face teaching. Use of technology and multimedia is described in details. Use of smart gadgets for different tasks like teaching, designing question papers, assessment of student, feedback and research methodology are discussed.
\end{abstract}

Index Terms-Blogging, pedogogy, podcast, pooling, smartboards, smartpen, screencast, social bookmarking, voive thresds, vikipedia.

\section{INTRODUCTION}

The objective of this work is to incorporate technology in to teaching learning methods to create a rich learning experience for students and a rewarding teaching experience for faculty.

The two educational models practiced across the globe are face to face learning and hybrid learning

The traditional method of teaching and learning is synchronous and typically involves the employment of a classroom where professor and students interact within time and space. This model of teaching is called synchronous.

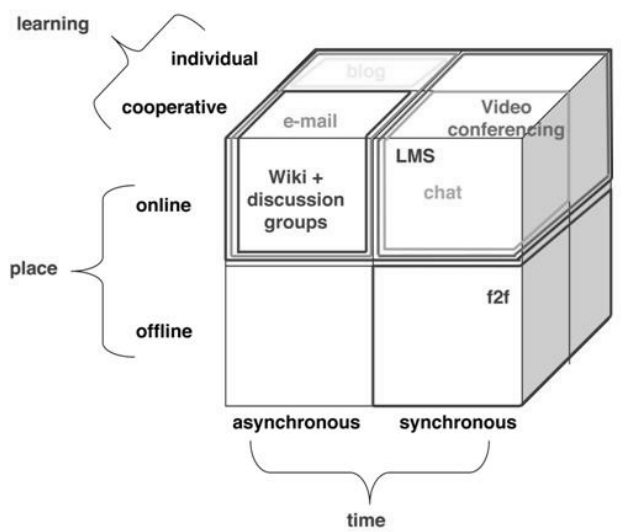

Fig. 1. Hybrid teaching and learning.

Interactions with face to face and distance learning techniques to disseminate information to members of a learning community. This type of learning blends technology based asynchronous teaching method and traditional teaching method.

The asynchronous or hybrid teaching has following advantages. It motivates the learning process. It offers time

Manuscript received May 23, 2014; revised July 31, 2014.

C. M. Khairnar is with Government College of Engineering Chandrapur, India (e-mail: cmkhairnar@gmail.com). flexibility for part time job or other assignment holders. It reduces overcrowded classrooms. Faculty can add more instructions overtime and maximizes student learning. Fig. 1 shows the hybrid teaching model

Students perspective is that they can interact better with the faculty and classmates, remain engaged. Improvement in students soft skills, critical thinking and problem solving. Compute skill and technical skills of students increase.

Faculty perspective is that they accomplish course teaching objective better, can re-evaluate course work material. The effectiveness of in-class activity increases. It encourages out-of-class learning.

\section{TEACHING WITH TECHNOLOGY}

\section{A. Why Technology}

Teaching with technology engages students with different kinds of stimuli- involve in activity based learning. Technology makes material more interesting. It makes students and teachers more media literate [1]. Fig. 2 shows the networked teacher who uses technology and gadgets.

Technology is a means to justify the end of composition outcomes and has become a seamless extension of the curriculum in the classroom. Technological Pedagogical Content Knowledge captures the qualities of this new hybrid educator who must find his or her place between the intersection of these qualities. To most effectively teach technology, we must model that technology within our disciplines and classes [2].

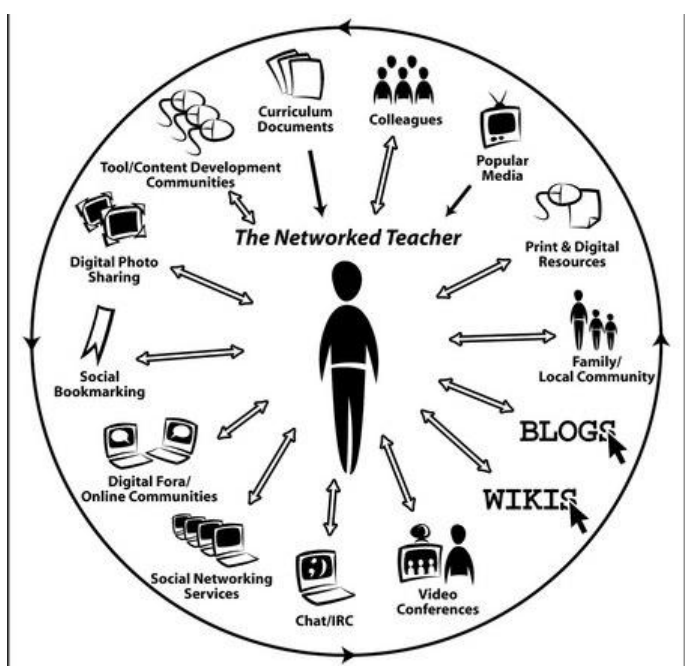

Fig. 2. The networked teacher using technology and gadgets.

\section{B. VoiceThreads to Build Student Engagement}

VoiceThread is a web service that allows users to upload 
PowerPoint slides, videos, photos, et al. and add voice narration to create a multimedia presentation.

VoiceThread is an application that runs inside your web browser (no software to download, install, or update) and it allows you to transform collections of media, like images, videos, documents, and presentations, into a place for a conversation. These conversations are not live, but take place whenever it's convenient for the people to participate. They are also secure, with simple controls that let you dictate who can participate and what they can do. Educators use VoiceThread for many different reasons, from extending and documenting classroom conversations, online tutoring, virtual class spaces, professional development training, and a thousand things in between.

The advantages of the voice thread are as follows. It starts student driven discussions with better understanding. It is a great way to deliver projects and solicit feedback.

The information about voice threads is available on the following links

1) VoiceThread

introduction: http://VoiceThread.com/\#u189469.b21651.i122786

2) Creating a VoiceThread: http://VoiceThread.com/\#q.b409.i848804

3) Student outcomes: http://VoiceThread.com/\#q+college.b99673.i508133

4) Art class example: http://VoiceThread.com/\#q+college.b8863.i62483

\section{Blogging}

Blogging is a public post. Blogging for study sessions is to be practiced. Students can post case studies in a class blog. Students can be asked to post notes on class blog. You can analyze, evaluate and create the material.

Blogging causes you to reflect. Teachers naturally think back on what has happened in their classroom, and often wonder what they could have done better. Blogging can help with this process, enabling teachers to keep an ongoing personal record of their actions, decisions, though processes, successes and failures, and issues they have to deal with. Blogging can crystallize your thinking. As we write, we invest a part of ourselves into the medium. The provisionality of the medium makes blogging conducive to drafting and redrafting. The act of composing and recomposing ideas can enable abstract thoughts to become more concrete. Your ideas are now on the screen in front of you; they can be stored, retrieved and reconstructed as your ideas become clearer. You don't have to publish if you want to keep those thoughts private. Save them and come back to them later. The blog can act as a kind of mirror to show you what you are thinking. Sometimes we don't really know what we are thinking until we actually write it down in a physical format.

\section{Prezi-Your Presentations}

Prezi is a new way to do the presentations. Prezi is a versatile app that lets you make professional-looking presentations. It's like a free, pared-down version of PowerPoint. Prezi lets you make presentations that are as casual or as professional as you want them to be. It allows you to add information to a prezi organize it in a logical way, embellish it with audio and video and then share it with the people you need to reach.
Prezi makes making a presentation very easy. The whole app flows very easily - even without looking at the intro or help, you can dive into a new presentation fairly competently. It is worth looking at the help and online resources to get the most out of it, but even taking Prezi in isolation, it's very usable.

Before Prezi, there was PowerPoint, and to a large extent, that was it. PowerPoint is a great piece of software, don't get us wrong, but there was definitely room for a change. Prezi feels fresh and easy, but still produces nice-looking presentations. It's also capable of dealing with feature-rich and complex material, and making it look good.

\section{E. Social Bookmarking}

Bookmarking is the simple process of saving the address of a website in the favorite folder of your web browser so that you can find it again later. Social-bookmarking takes this process two steps further. Firstly, instead of saving the bookmarks to your favorite folder, it saves them online. The great advantage of this is that you can then access them from any computer, not just the one you saved them on, simply by logging into your social-bookmarking account. This enables you to access your favorite sites from wherever you are, rather than wherever you bookmarked the site. The second advantage is the social part. Saving bookmarks online enables you to easily share them with other internet users and for you to access their bookmarks as well. This can help you find and access many more useful websites, especially as many social-bookmarking sites enable you to join special interest groups and find people who have similar interests to you.

The benefits of social bookmarking is that it is easy to share and manage social bookmarks. Searching and storing in database is also easy.

\section{F. Podcast in Classroom}

Podcasts are serial recordings, posted regularly online.. Basically, producing podcasts is the technology-based equivalent of oral lectures. Much as lectures and news have been shared with listeners, who download the files online.

The advantages of podcast is its flexibility, reusability of your lecture. It is advantage for the hearing impared students.

\section{G. Screencast}

Screencasts have emerged as a prominent teaching tool on the Internet. Screencasts are an effective way to share ideas, deliver content, and obtain student feedback. Screencasts can be used for describing a step-by-step process, explaining a particular concept, or presenting a PowerPoint presentation with narration and multimedia elements. A screencast can be used in any class as a part of real-time instruction or as the lesson itself as in the flipped teaching model. With the flipped teaching method, instructors use screencast videos to deliver their lectures, assigning them as homework. Then, in class, students can ask questions as they work through problems that they normally would have done at home without teacher help. Creating an educational screencast that meets content objectives requires a systematic approach to planning. It seems clear that screencasting is a powerful, highly effective, and affordable learning tool that can facilitate learning across any curriculum area. Screencasting 
is a remarkable instructional tool.

These are the free software's available for instructors which teach and saves time. Jing, Screen jelly, screenR, Screencast are some of the freebies available.

\section{H. Social Media in to Education}

A social media where individuals are in communities that share ideas and interests. Some popular communities are: Facebook, Myspace, Youtube, blogs, Twitter and delicious.

Facebook and other social media have been hailed as delivering the promise of new, socially engaged educational experiences for students in undergraduate, self-directed, and other educational sectors.

Concerns of social media Concerns: Loss of control, Time commitment, Unnecessary information, Information overload Anyone can create official account for your university

\section{Pooling to Keep Students Engaged}

Polling can be used as a means of reflection in generating an issue for Science experiments, Discipline, Understanding and feedback [3].

Using polling and smart phones to keep students engaged

1) Poll Everywhere (http://www.polleverywhere.com) Unlimited polls with up to 30 respondents on the free plan.

2) Flisti (http://flisti.com)Super easy polling system. No signup required.

3) MicroPoll (http://www.micropoll.com)Good for creating a poll to embed in a blog or some other website.

4) Vorbeo (http://vorbeo.com) Another system for creating a poll to embed in your website.

5) Polldaddy (http://www.polldaddy.com) Free and paid plans available.

6) TextTheMob (http://textthemob.com) Free plan allows for up to three questions with 50 responses.

\section{J. Lecture Capture}

Knowledge is to be shared globally and published for generations to come. With the following links you can have wonderful lecture capture and video lecture. TED- Short lecture, iTunesU- apples.com/education/ipodtouch-iphone/ Free video lectures-18,000- freevieeolectures.com, Videolectures.com- Great lecture exchange.

\section{K. Cool Gadgets for Classrooms}

Smartpen by lifescribe: Smartpens are able to Capture transmitted information, replay it and sent it. It is like wireless transfer of your ideas anywhere, anytime and ready to share with students and vice versa. During lecture smartpen helps students, when teeacher talk fast, student can record and understand all the leftout things. Smartpens can record video, audio and diagrams - you can listen and understand during lecture.

\section{Smart Boards}

Smart products bring learning to life, helping students experience a deeper level of engagement and understanding by making course content interactive and visual. The ease of use built in to each product enhances instructional efficiency. Instructors can begin delivering course material with the simple touch of a finger or a pen, save comments and notes made in digital ink, and distribute saved content directly to students.

Smart products are flexible, complementary and evolving. This means the products you choose today will work together now and in the future as your technology requirements change.

Smartboard-Interactive Whiteboard: Transform your learning spaces into interactive, collaborative environments where students are both inspired and focused. With a SMART Board interactive whiteboard, instructors can interact with dynamic multimedia content and write notes in digital ink, then save them instantly and distribute this material to students with ease. SMART Board interactive whiteboards make learning a visual, engaging experience for students, which helps deepen understanding and promote retention of course material.

\section{Wikipedia in the Classroom-Tips for Effective Use}

Studies have shown the Wikipedia is about as accurate as Britannica. Writing articles transforms students into teachers, which improves outcome. Creating public work improves motivation and performance. Receive feedback from Wikipedia editors-FA team

Good article- one on 800 and feature article- one in 2000 More than 20 universities have projects in Wikipedia.

With number of hits per month, you understand value of your work.

Host course in Wikiversity:

1) Wikimedia-a non-profit foundation that created Wikipedia- also hosts:

2) Wikibooks(free text books)

3) Wikispecies(Dictionary of species)

4) Wikiquote(Compilation of Quotes)

5) Wikiversity (Space for hosting courses or other content) Wikiversity

6) Faculty can develop course page with syllabi, lesson plans, and other notes for students to access whenever they need. Page can also be linked to videos

7) Student and groups can be given access to add more material.

8) Develop free web-based quiz for future students [4].

9) Enlist students on an ongoing project of developing knowledge for future generations of students.

\section{N. Personal Learning Environment-Learning beyond Classroom}

1) Create an environment to think beyond

2) Allow students to think beyond in assignments

3) Let them design their imagination

Effective use of videos and creative way of thinking to boost learning. Remixing technology and creativity and education gives excellent results [5].

\section{O. Moodle}

It is Open source system to help design your session. Moodle is Virtual Learning Environment which provides staff and students with access to electronic teaching and learning materials such as lecture notes and links to useful websites and activities such as discussion forums, group assignments, reflective journals and quizzes.

\section{P. Evernote}


It is something that lets you capture your experience, note, website, photos. Evernote is also a great tool for teachers and students to organize all of their own content. One can download the application. They can organize all of their notes and handouts in an Evernote notebook-it's portable, searchable, indestructible. Even if you they lose their phone, their data is safe in the Cloud. In addition to systematizing notes for class, it's a great tool to use for research activities-students can store images, PDFs, and even hand-written notes.

\section{Q. Many Teaching Options}

\section{1) Chat rooms}

2) Discussions board

3) Webinars

4) Emails

5) Social media in class rooms

6) Image creators

- Motivator (motivational http://bighugelabs.com/motivator.php)

- Imagechef (banners,signs, (http://www.imagechef.com/)

- Cameroid (edit images from camera): http://www.cameroid.com/
- Create many interensting (http://www.fodey.com/)

\section{CONCLUSION}

Any teaching method without destroying the objective could be considered as innovative methods of teaching. The researchers believe that the core objective of teaching is

passing on the information or knowledge to the minds of the students. There are a number of ways that teachers can bypass the system and offer students the tools and experiences that spur an innovative mindset.

\section{REFERENCES}

[1] S. B. King, "Graduate student perceptions of the use of online course tools to support engagement," International Journal for the Scholarship of Teaching and Learning, vol. 8, no. 1, pp. 130-132, 2014.

[2] R. Darda, Handbook on Advanced Pedagogy, Monarch University Publications, 2014, ch. 2, pp. 45-46.

[3] E. Gunn, "Using clickers to collect formative feedback on teaching: a tool for faculty development," International Journal for the Scholarship of Teaching and Learning, vol. 8, no. 1, article 11, 2014.

[4] C. J. Bonk and J. A. Cummings, "Rrecommendations for placing the student at the centre of web-based learning," Educational Media International, vol. 35, no. 2, pp. 82-89, 1998.

[5] S. Ashton, T. Roberts, and L. Teles, "Investigation the role of the instructor in collaborative online environments," presented at the CSCL '99 Conference, Stanford University, CA, 1999.

posters):

buttons)

projects:

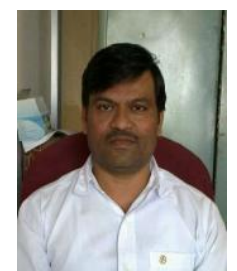

C. M. Khairar was born on December 26, 1970 in Jalgaon, Maharastra, India. He received his M.Sc. Pune MS India 1991, and Ph.D. Amravati, MS India 2002 He studys modern physics, thin films, Glassy semiconductors, quality in technical education.

$\mathrm{He}$ worked as a lecturer in Anuradha Engineering College, Chikhli, MS, India from 22 Jul. 1994 to 5 Nov. 2003, and he was an associate professor in Government College of Engineering Chandrapur from 6 Nov 2003 till date.

He has published several papers, for example, Modern physics (jalgaon, MS, India: chanakya, 1995), etc.. He is a member of Indian Society for Technical Education, Delhi, Materials Research Society of India, Bangalore, and so on. 